\title{
Do all organic chemists deal with high-purity substances?*
}

\author{
I. A. Revelsky
}

\author{
Department of Chemistry, M. V. Lomonosov Moscow State University, \\ 1 Leninskye gory, building 3, 119991 Moscow, GSP-1, Russian Federation. \\ E-mail: revelsky@environment.chem.msu.ru
}

\begin{abstract}
High-precision data of $\mathrm{C}, \mathrm{H}, \mathrm{N}$ elemental analysis published in journals for any synthesized organic compound are not always true. Such precise results can be obtained only for high-purity organic compounds (purity degree of $>99 \%$ ). However, in determination of the purity of highpurity organic compounds, in particular, pharmaceutical substances and drugs, elemental analysis is either superior or equivalent to the generally accepted methods as it is versatile, fast, and does not require the use of standard analyte samples.
\end{abstract}

Key words: purity control, elemental analysis, high-purity organic compounds.

The editorial departments of all journals that publish papers dealing with synthesized organic compounds require presenting the experimental data on the content of elements such as $\mathrm{C}, \mathrm{H}$, and $\mathrm{N}$ in the analyte molecules obtained using an elemental analyzer. It is considered that the difference between the theoretical and experimental values on the element percentages in the molecule should not exceed $0.3,0.05$, and $0.1 \%$ for $\mathrm{C}, \mathrm{H}$, and $\mathrm{N}$, respectively. However, until now, nobody paid attention to the fact that the specified errors of determination of the element percentages can be met only for high-purity compounds (purity degree $>99 \%$ ).

However, it is obvious that not all organic compounds prepared by organic chemists are high-purity chemicals, as it is often impossible to prepare such chemicals using the standard equipment of a synthetic laboratory. This means that published experimental data on the percentages of elements in a molecule are not correct (i.e., not true) for many compounds. Perhaps, some of the data have not been found experimentally but have been determined by calculations for the corresponding compounds identified by NMR or mass spectrometry. Therefore, various databases containing properties of organic compounds that depend on the degree of compound purity can give faulty values.

Meanwhile, organic elemental analysis can be a versatile method for determining the degree of purity of highpurity organic compounds, ${ }^{1-4}$ including pharmaceuticals. In its potential, this method is either superior or equivalent to the generally accepted methods. Apart from high accuracy, advantages of this method are versatility, high speed, and the absence of necessity to use standard samples of the analyte.

Previously, we demonstrated the possibility of fast screening of samples of pharmaceutical agents for the content of the active component by using elemental analysis. ${ }^{5}$ The extensive introduction of this method of analysis would increase the level of quality control of pharmaceutical products and would create conditions for solving the topical problem: disclosure of adulterated products.

\section{References}

1. I. A. Revelsky, E. S. Chernetsova, B. P. Luzyanin, I. N. Glazkov, A. A. Shnaider, Zav. labor., 2007, 73, No. 7, 20-25 [Ind. Lab. (Engl. Transl.), 2007, 73].

2. I. A. Revelsky, E. N. Kapinus, M. V. Fedoseeva, G. N. Gil'deeva, V. V. Kosenko, A. I. Revelsky, Zh. Analit. Khim., 2009, 64, 949-953 [J. Anal. Chem. (Engl. Transl.), 2009, 64].

3. I. A. Revelsky, E. S. Chernetsova, B. P. Luzyanin, M. V. Fedoseeva, I. N. Glazkov, A. I. Revelsky, Drug Testing and Analysis, 2010, No. 2, 452-454.

4. M. V. Fedoseeva, Ph. D Thesis, M. V. Lomonosov Moscow State University, Moscow, 2012, 112 pp. (in Russian).

5. I. A. Revelsky, V. V. Kosenko, E. S. Chernetsova, M. V. Fedoseeva, L. I. Mit'kina, B. P. Luzyanin, A. I. Revelsky, Vestn. Roszdravnadzora (Bull. of the Federal Service on Surveillance in Healthcare and Social Development of Russian Federation), 2009, No. 3, 27-31 (in Russian).

\footnotetext{
* Based on the materials of the First Russian Conference on Medicinal Chemistry ("MedChem Russia-2013") with International Participation (September 8-12, 2013, Moscow).
}

Received April 22, 2014

Published in Russian in Izvestiya Akademii Nauk. Seriya Khimicheskaya, No. 5, p. 1259, May, 2014.

1066-5285/14/6305-1259 (C) 2014 Springer Science+Business Media, Inc. 